\title{
Cluster Preface: Special Edition Dedicated to ISySyCat2019
}

\author{
Anthony J. Burke* \\ Chemistry Department, University of Évora, School of Science and \\ Technology, Institute for Research and Advanced Training (IIFA), \\ Rua Romão Ramalho, 59, 7000-671 Évora, Portugal \\ ajb@uevora.pt \\ Published as part of the ISySyCat2019 Special Issue
}

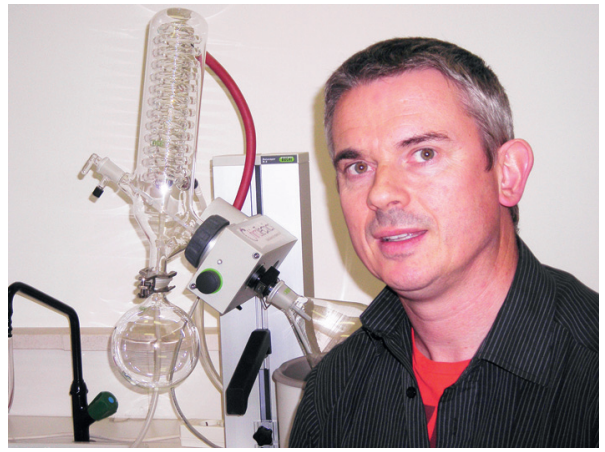

Received: 20.01.2020

Accepted: 20.01.2020

Published online: 18.03 .2020

DOI: 10.1055/s-0040-1708008; Art ID: st-2020-b3333-c

Anthony J. Burke obtained his B.Sc. (joint honors in chemistry \& biology, 1988) from NUI-Maynooth and his Ph.D. from University College Dublin, Ireland (1993, supervisor: W. Ivo. O'Sullivan). After postdoctoral studies with Steve Davies (Oxford, 1993-1996) and Chris Maycock (ITQB Portugal, 1996-1999) and working for a year as a lecturer in analytical chemistry at Instituto Piaget: Instituto Superior de Estudos Interculturais e Transdisciplinares, Almada, Portugal, he accepted a position as assistant professor in organic chemistry, at the University Évora. He obtained the title of aggregation ('habilitation') in organic chemistry from the University of Évora in 2012 and was recently appointed to the position of associate professor at the same department. He was chairman for of 1st, 2nd and 3rd editions of the International Symposium on Synthesis and Catalysis (ISySyCat), and is actively planning the 4th edition for 31 Aug to 3 September, 2021. He was appointed a Fellow of ChemPubSoc Europe in Feb 2020.

The International Symposium on Synthesis and Catalysis (ISySyCat) is a biannual conference in the field of chemical synthesis (with a leaning toward organic synthesis) and catalysis. It takes place at the University of Evora, in the oldest and classical part that boasts a history of almost 500 years. This was actually the seat of learning of numerous Jesuit novices, who studied-besides the usual classics-innovative topics for that time, like astronomy, physics, and geometry.

The philosophy behind ISySyCat is the promotion of the exploits of both academic and industrial researchers in the aforementioned fields.

ISySyCat2019 took place between the 3rd and 6th of September 2019 and welcomed over 300 attendees from over 37 countries. ISySyCat2019 spanned all the various subclasses within the broad field of synthesis and catalysis as is seen by the selection of topics in this special edition. Topics range from total synthesis, catalysis, synthetic meth- odology and medicinal chemistry to industrial synthesis. The presentations came from both academic and industrial chemists.

Two of the contributions to this special issue were accounts from renowned experts. These are an article by Benaglia and Rossi (University of Milan) on the development of new chiral biheteroaromatic chiral bisphosphine oxides (BITIOPO) for Lewis base catalyzed and Lewis acid mediated stereoselective transformations, ${ }^{1}$ and another from Sodeoka (plenary speaker) and Sohtome (Riken Center and Cluster, Saitama, Japan) on multiselective catalytic asymmetric reactions using $\alpha$-keto esters as pronucleophiles or formal 1,3-dipolarophiles. ${ }^{2}$

The remaining contributions were research papers. Starting with Massé and co-workers (University of Strasbourg/University of Basilicata, Italy) who presented their work on the application of a sequential Suzuki-Miyauraring-closing metathesis for the synthesis of the strained $[7,0]$-metacyclophane, myricanol (we learn that in fact it was unintentional!). ${ }^{3}$ Coelho and co-workers (University of Campinas, Brazil) contributed an article on the application of the aza-Morita-Baylis-Hillman reaction with vinyl-oxadiazoles to give a new class of heterocycle. ${ }^{4}$ Garrido and coworkers (University of Salamanca, Spain) reported on the synthesis of chiral 2,3,6-trisubstituted piperidines via chiral lithium amide addition (pioneered by Steve Davies) to Baylis-Hillman adducts. ${ }^{5}$ Baylis-Hillman substrates were also in evidence in the contribution by Vilotijevic and co-workers (Friedrich Schiller University Jena, Germany) that concerned the synthesis of enantioenriched chiral $\beta$-lactams via the enantioselective allylation of anilines using MoritaBaylis-Hillman carbonates (of note was the use in this work of the cinchona (DHQD) ${ }_{2} A Q N$ dimeric organocatalyst). ${ }^{6}$ Schomaker (plenary speaker) and co-workers (University of Wisconsin) reported on the rapid entry to fivemembered carbocyclic frameworks (common to pharma- 
ceuticals and natural products) via stereodivergent metalcatalyzed allene cycloisomerizations (it was shown that there was a dichotomy in the cyclization direction, with Pd preferentially affording the syn-diastereomer and Au preferring to give the anti-diastereomer). ${ }^{7}$ Gosselin (plenary speaker) and his team from Genentech Inc. (CA, USA) reported on the high-yielding, operationally simple synthesis of 2,3-disubstituted pyrazoles via magnesium-catalyzed N2-regioselective alkylation of 3-substituted pyrazoles. ${ }^{8}$ Pinho e Melo and co-workers (University of Coimbra, Portugal) reported on a one-pot synthetic methodology for accessing chiral 2-(tetrazol-5-yl)-2H-azirines, involving an in situ ketoxime tosylation followed by a rare organocatalyzed asymmetric Neber reaction. ${ }^{9}$ Carreiro and co-workers (University of Evora, Portugal) reported a sequential coppercatalyzed alkyne-azide cycloaddition (CuAAC)-multicomponent Biginelli reaction for the synthesis of novel 1,2,3-triazole-dihydropyrimidinone products that showed good antitumor activity. ${ }^{10}$ Sticking with the theme of 1,2,3-triazole synthesis, Roux and Cisnetti (University of Clermont Auvergne, France) reported on a sequential SonogashiraCuAAC process leading to suitably substituted triazoles. This was demonstrated to be a safe and simple means of accessing triazole targets as there was no need to isolate the 2-nitrophenyl azides. ${ }^{11}$ Díez-González and co-workers (Imperial College London) reported on a one-pot, metal-free synthesis of 1,2,3-triazoles in deep eutectic solvents (the reactions involve the addition of aryl azides bearing trifluoromethyl groups with enol ethers and proceed via a cycloaddition/elimination cascade). ${ }^{12}$ Hansen and Elumalai (The Arctic University of Norway) reported on a substantially improved synthesis of substituted benzimidazoles by condensation of 1,2-diaminoarenes and aldehydes in air (1 min) under microwave- and additive-free conditions. ${ }^{13}$ In the field of radical chemistry, Maulide (plenary speaker) and co-workers (University of Vienna) reported a one-pot procedure for the direct formation of $\alpha$-functionalized thioesters through the aminoxylation of thioalkynes via a radical-polar crossover mechanism. ${ }^{14}$ Guieu and co-workers (University of Aveiro, Portugal) reported the use of simple building blocks as starting materials for the preparation of 1,2,4-triphenylpyrroles. The synthetic route encompassed an aldol condensation, a Michael addition, a Nef reaction and a Paal-Knorr reaction as the final step. ${ }^{15}$ In the area of flow chemistry, Smyth and Manyar (Almac Sciences Ltd., Craigavon and Queen's University Belfast) reported the use of a custom-built packed-bed flow hydrogenation rig for the FAST (flow-assisted synthesis technology) hydrogenations of aromatic nitrobenzoic acids in water to produce the corresponding anilines. ${ }^{16}$ Volochnyuk, Ryabukhin and coworkers (Enamine Ltd., the National Academy of Sciences of Ukraine and the Taras Shevchenko National University of Kyiv) reported on the semi-industrial fluorination of $\beta$-keto esters with $\mathrm{SF}_{4}$ leading to gem- $\beta$-difluoro esters (and ultimately gem- $\beta$-difluoro acids after hydrolysis). ${ }^{17}$ Finally, Bo $\mathrm{Qu}$ and colleagues (Boehringer Ingelheim Pharmaceuticals and University of Pennsylvania) presented the rational design of new dihydrobenzooxophosphole-based Lewis base organocatalysts. ${ }^{18}$

I would like to thank the SYNLETT team at Thieme, and particularly Prof. Ben List (for giving the green-light for this special issue), for their exceptional professionalism and for making this possible.

As a final remark, for those who want to share this experience, we will be back with ISySyCat21 from the 31st of August to the 3rd of September 2021, which we hope will be as successful as this edition.

Anthony J. Burke

(Conference Chairman)

\section{References}

(1) Rossi, S.; Benincori, T.; Raimondi, L. M.; Benaglia, M. Synlett 2020, 31, 535.

(2) Sohtome, Y.; Sodeoka, Mi. Synlett 2020, 31, 523.

(3) Massé, P.; Choppin, S.; Chiummiento, L.; Hanquet, G.; Colobert, F. Synlett 2020, 31, 559.

(4) Capretz-Agy, A.; Fernandes, F. S.; Rodrigues, M. T.; Conti, C.; Coelho, F. Synlett 2020, 31, 622.

(5) Salgado, M. M.; Manchado, A.; Nieto, C. T.; Díez, D.; Garrido, N. M. Synlett 2020, 31, 600.

(6) Zi, Y.; Lange, M.; Schüler, P.; Krieck, S.; Westerhausen, M.; Vilotijevic, I. Synlett 2020, 31, 575.

(7) Reeves, R. D.; Kinkema, C. N.; Landwehr, E. M.; Vine, L. E.; Schomaker, J. M. Synlett 2020, 31, 627.

(8) Xu, D.; Frank, L.; Nguyen, T.; Stumpf, A.; Russell, D.; Angelaud, R.; Gosselin, F. Synlett 2020, 31, 595.

(9) Alves, C.; Grosso, C.; Barrulas, P.; Paixão, J. A.; Cardoso, A. L.; Burke, A. J.; Lemos, A.; Pinho e Melo, T. M. V. D. Synlett 2019, 30, 553.

(10) Carreiro, E. P.; Sena, A. M.; Puerta, A.; Padrón, J. M.; Burke, A. J. Synlett 2020, 31, 615.

(11) Roux, A.; Cisnetti, F. Synlett 2020, 31, 610.

(12) Sebest, F.; Haselgrove, S.; White, A. J. P.; Díez-González, S. Synlett 2020, 31, 605.

(13) Elumalai, V.; Hansen, J. H. Synlett 2020, 31, 547.

(14) Di Mauro, G.; Drescher, M.; Tkaczyk, S.; Maulide, N. Synlett 2020, 31, 592.

(15) Ferreira, J. R. M.; Nunes da Silva, R.; Rocha, J.; Silva, A. M. S.; Guieu, S. Synlett 2020, 31, 632.

(16) Rahman, M. D. T.; Wharry, S.; Smyth, M.; Manyar, H.; Moody, T. S. Synlett 2020, 31, 581.

(17) Trofymchuk, S. A.; Kliukovskyi, D. V.; Semenov, S. V.; Khairulin, A. R.; Shevchenko, V. O.; Bugera, M. Y.; Tarasenko, K. V.; Volochnyuk, D. M.; Ryabukhin, S. V. Synlett 2020, 31, 565.

(18) Qu, B.; Samankumara, L. P.; Saha, A.; Schumer, M. G. S.; Han, Z. S.; Haddad, N.; Busacca, C. A.; Yee, N. K.; Kozlowski, M. C.; Song, J. J.; Senanayake, C. H. Synlett 2020, 31, 587. 